\title{
Comparison of ketamine-propofol mixture (ketofol) and midazolam-meperidine in endoscopic retrograde cholangiopancretography (ERCP) for oldest old patients
}

This article was published in the following Dove Press journal:

Therapeutics and Clinical Risk Management

Tarıkçı Kılıç Ebru'

Kahraman Resul ${ }^{2}$

'Department of Anesthesiology, Ümraniye Training and Research Hospital, İstanbul, Turkey; ${ }^{2}$ Department of Gastroenterology, Ümraniye Training and Research Hospital, İstanbul, Turkey
Correspondence: Tarıkçı Kılıç Ebru Department of Anesthesiology, Ümraniye Training and Research Hospital, Adem Yavuz Street, No:I, Ümraniye/İstanbul, Turkey Tel +905063306640

Fax +02166327I 24

Email ebru.tarkc@yahoo.com

Kahraman Resul

Department of Gastroenterology, Ümraniye Training and Research Hospital, Adem Yavuz Street, No:I, Ümraniye/İstanbul, Turkey Tel +905324404720

Email drkahraman@hotmail.com
Background and aim: Endoscopic retrograde cholangiopancreatography (ERCP) requires moderate-to-deep conscious sedation. Combinations of ketamine and propofol (ketofol) and of midazolam and meperidine were analyzed using the bispectral index (BIS). There is no research on the use of ketofol on very elderly patients. The aim of this study is to use BIS and offer insight into the use and safety of ketofol sedation for oldest old patients undergoing ERCP.

Materials and methods: For the ERCP procedure, 168 patients aged $85+$ years were enrolled in a 2-year retrospective single center study. Seventy-five patients received midazolam-meperidine (MM) sedation in 2016, while 75 patients received ketofol (KP) sedation in 2018.

The two groups were compared for patient data, procedure duration, Ramsay Sedation Score (RSS), heart rate (HR), blood pressure (BP), and pulse oximetry $\left(\mathrm{SpO}_{2}\right), \mathrm{BIS}$, facial pain score (FPS), time to achieve BIS, recovery time, and complications. The total amount of rescue medication was recorded.

Results: The two groups did not differ by patient data or procedure duration $(p>0.05)$. Group KP had significantly higher systolic and diastolic BP, HR, and $\mathrm{SpO}_{2}$ values and lower BIS scores than Group MM ( $p=0.0001)$. The two groups did not differ by time to achieve BIS scores $(p>0.05)$. Group KP had significantly fewer complications and a shorter recovery time than Group MM $(p<0.001)$.

Conclusion: Ketofol induced sedation results in more stable vital signs and fewer complications than the midazolam-meperidine sedation regimen during ERCP in oldest old patients, indicating that ketofol can be an alternative to midazolam-meperidine.

Keywords: ketofol, midazolam-meperidine, moderate to deep sedation, endoscopic retrograde cholangiopancreatography (ERCP), bispectral index (BIS), oldest old

\section{Introduction}

Endoscopic retrograde cholangiopancreatography (ERCP) is a gold standard treatment of biliary tract diseases that require moderate-to-deep sedation. ${ }^{1}$

A distinction should be made between moderate and deep sedation needs. In moderate sedation, patients can respond to verbal commands and/or tactile stimulations while maintaining adequate spontaneous ventilation and cardiovascular functions. However, in deep sedation, patients respond to repeated and/or painful stimuli 
but have all protective reflexes intact with spontaneous respiration, require assistance to maintain the airway, and cardiovascular functions may be compromised. ${ }^{2,3}$

The percentage of deep sedation episodes was $26 \%$ for ERCP, and the percentage of patients experiencing at least one episode of deep sedation was $85 \%$ in the very elderly. ${ }^{4}$ ERCP is an invasive procedure during which patients with poor general health secondary to old age and multiple associated diseases are more vulnerable to potential complications mainly caused by respiratory and cardiovascular conditions such as hypertension, hypotension, bradycardia, oxygen desaturation, abdominal discomfort, and dizziness, which may occur during operation. 5,6

Anesthesiologists use different doses and anesthetic agents depending on factors such as age, comorbidities, American Society of Anesthesiologists (ASA) score, reason for ERCP procedure, and time for procedure completion. Protective reflexes are not compromised, and cardiac functions are little affected by low doses of anesthetics. However, the procedure is interrupted or terminated due to patient agitation in some clinical situations. Deeper sedation is generally considered safe, unless the patient has underlying comorbidities which may increase the risk of aspiration. $^{7-9}$ Ketamine and propofol were mixed in different concentrations in the same syringe (ketofol) for procedural sedation. ${ }^{10-14}$

The administration of benzodiazepines such as midazolam, which contains an opioid like meperidine, requires the titration of doses of sedative agents. ${ }^{15-17}$ Bispectral index (BIS) is a non-invasive technology that provides valuable data used to assess the level of sedation and BIS values that have good correlation with Ramsay Sedation Score (RSS). ${ }^{18,19}$ There is limited data on the use of BIS in very elderly patients during sedation. ${ }^{20}$

We hypothesized that a subdissociative dose of ketamine is safer than the combination of midazolam and meperidine for sedation during ERCP. We aimed to use BIS to show that ketofol sedation is safe to use for oldest old patients undergoing ERCP.

To this end, we compared the patient data, procedure duration, heart rate (HR), blood pressure (BP), and pulse oximetry $\left(\mathrm{SpO}_{2}\right)$, BIS, Ramsay Sedation Score (RSS), facial pain score (FPS), recovery time, and complications of Group MM (75 patients), who received midazolammeperidine sedation in 2016, and Group KP (75 patients), who received ketofol sedation in 2018.

\section{Methods}

The initial sample consisted of 168 patients aged $85+$ years. However, 14 patients did not meet the inclusion criteria and four patients had missing data. Therefore, the final sample consisted of 150 patients. The study was approved by the Ethics Committee of Ümraniye Training and Research Hospital (B. 10.1.TKH.4.34.H. GP.0.01), and written informed consent was obtained from participants according to the guidelines presented in the Declaration of Helsinki.

The records of Groups MM and KP were compared. The exclusion criteria were as follows: 1) ASA V, 2) younger than 85 years of age, 3) presence of epilepsy, arterial aneurysm, or intracranial mass, 4) history of drug allergy, and 5) presence of hemodynamical instability such as peripheral oxygen saturation $<90 \%$, systolic blood pressure (SBP) $<60 \mathrm{mmHg}$ and $\mathrm{HR} \leq 40 \mathrm{bpm}$.

Two experienced anesthesiologists administered sedation to patients. Groups MM and KP did not differ by the duration of the procedure conducted by two endoscopists who had over 5 years of experience in ERCP.

Patients were referred to the endoscopy unit. Twentygauge intravenous catheters were inserted, and $10 \mathrm{~mL} / \mathrm{kg} / \mathrm{h}$ of isotonic infusion was administered. Patients were laterally positioned and monitored for HR, SBP, diastolic blood pressure (DBP), peripheral oxygen saturation $\left(\mathrm{SPO}_{2}\right)$, and bispectral index (BIS). Data were recorded at preinduction ( $\mathrm{t} 0$ ), at ( $\mathrm{t} 1)$ following induction and at ( $\mathrm{t} 2)$ 10 minutes and (t3) 30 minutes. Supplemental oxygen was administered using a nasal cannula at the beginning of the procedure. FPS (0-10) was used to evaluate pain at (t1), (t2), and (t3) (Figure 1). Time to achieve RSS scores $\geq 4$ was recorded (Figure 2). Procedure duration was defined as the time between the insertion of the endoscope and the end of the procedure. Drug infusion was discontinued at the end of the procedure. Recovery time was defined as the time from the termination of drug infusion until the achievement of a Modified Aldrete Score (MAS) (9-10). $\mathrm{SPO}_{2}<90 \%$ for more than 10 seconds was defined as respiratory depression. Apnea was defined as the cessation of airflow for at least 20 seconds. Hypotension was recorded at $\mathrm{SBP}<70 \mathrm{mmHg}$, and bradycardia was taken into account when $\mathrm{HR}<50 \mathrm{bpm}$.

Bolus was administered to Group KP. They received $0.5 \mathrm{mg} / \mathrm{kg}$ ketamine and $0.5 \mathrm{mg} / \mathrm{kg}$ propofol intravenously. Afterwards, ketofol (1:1) consisting of $2 \mathrm{~mL}$ ketamine $(50 \mathrm{mg} / \mathrm{mL})$ and $10 \mathrm{~mL}$ propofol $(10 \mathrm{mg} / \mathrm{mL})$, while $8 \mathrm{~mL}$ normal saline containing $5 \mathrm{mg}$ ketamine and $5 \mathrm{mg}$ 

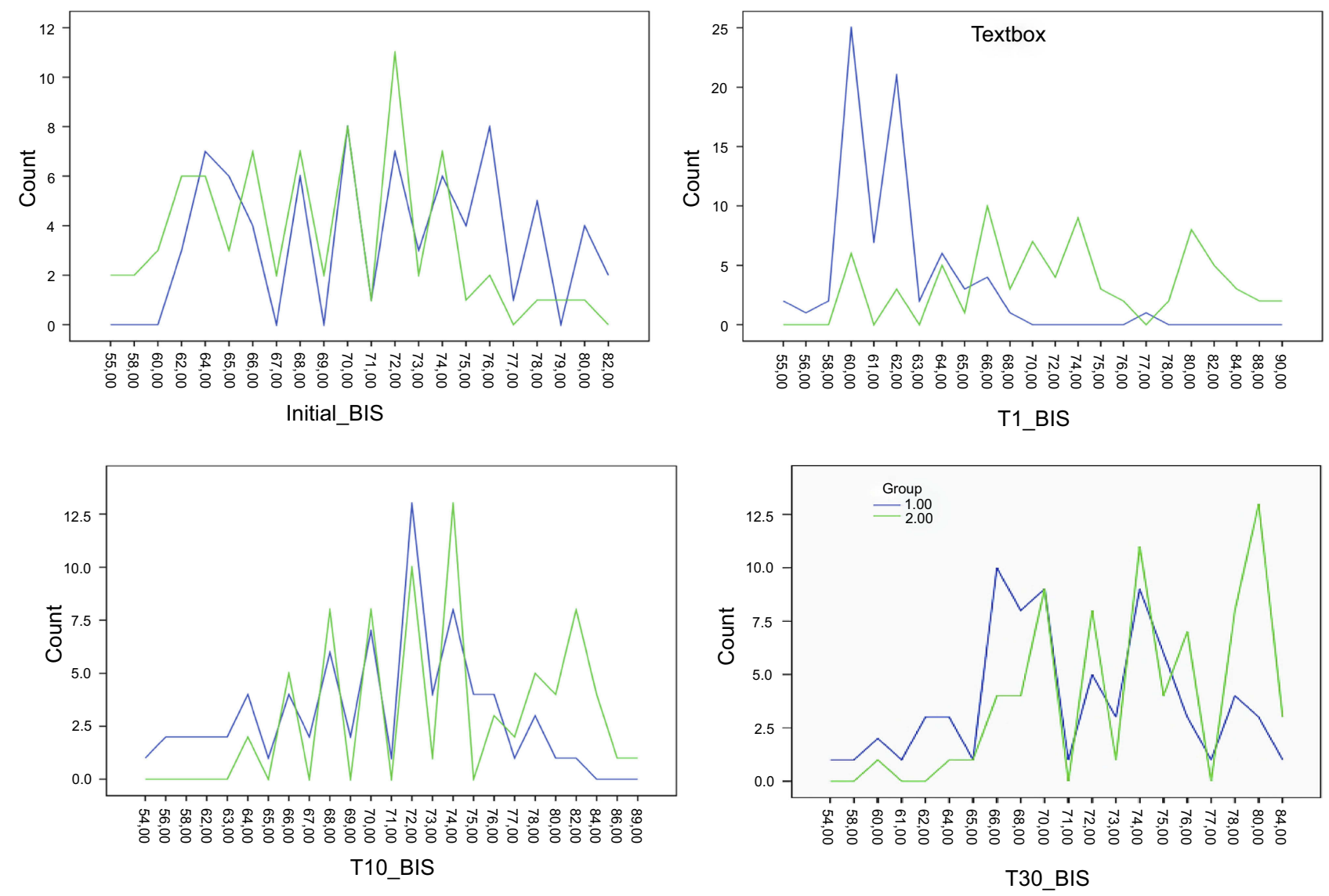

Figure I Distribution of BIS scores of each groups. The $y$-axis presents BIS level and the $x$-axis presents the number of patients. Abbreviation: BIS, bispectral index.

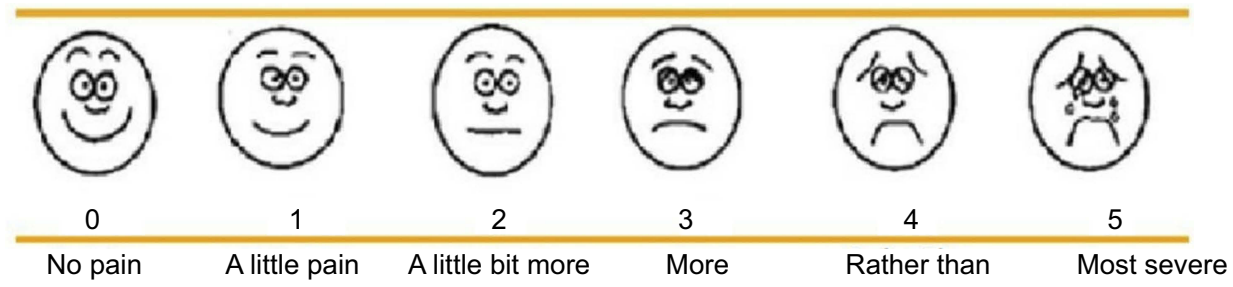

Figure 2 Facial pain score.

propofol for each milliliter was titrated to maintain a BIS ranging from $60-80$ and $\mathrm{RSS} \geq 4$. Midazolam $(2.5 \mathrm{mg})$ and meperidine $(0.5 \mathrm{mg} / \mathrm{kg})$ were administered as intravenous bolus doses to Group MM for induction. They intravenously received single injections of $1 \mathrm{mg}$ midazolam depending on RSS level of sedation and BIS monitorization ranging from $60-80$ throughout the procedure. No continuous anesthetic infusion was used in Group MM. When the RSS score reached 4, the procedure was started with the insertion of the endoscope by the endoscopist. We monitored BIS and RSS values for dose adjustment of anesthetics during the procedure.

In cases where the endoscopist or patient felt uncomfortable or the patient needed to cough, gag, or needed restraint or FPS $>5$, participants were injected with another dose (ie, increment dose of $10 \mathrm{mg}$ ) of rescue sedation (propofol), the total amount of which was recorded. Post-ERCP recovery was based on MAS. Patients with a MAS $\geq 9$ were discharged. The anesthesiologist monitored postoperative MAS for 1 minute and every 5 minutes during the follow- 
up period. Hypotension, respiratory depression, bradycardia, nausea, vomiting, and emergence reactions such as delirium and excitement were recorded during the recovery period. Ephedrine $(5 \mathrm{mg})$ or atropine $(0.5 \mathrm{mg})$ were administered if $\mathrm{SBP}<70 \mathrm{mmHg}$ and/or HR $<50 \mathrm{bpm}$.

The primary outcomes were: 1) the amount of propofol used as a rescue medication; and 2) time of reaching RSS $\geq 4$. The secondary outcomes were: 1) the duration of postoperative recovery based on MAS $\geq 9$; and 2) the prevalence of respiratory depression, laryngospasm, and nausea/vomiting, and the incidence of other side-effects such as bradyarrhythmia and/or change in circulatory dynamics. Groups MM and KP were compared in terms of these outcomes. Head tilt/chin lift maneuver or mask ventilation technique were used when needed.

\section{Statistical methods}

Frequencies were calculated for nominal and ordinal data, which were analyzed using chi-square and chi-square with Linear Likelihood ratios. Mean and standard deviation (SD) were presented for scale parameters. The KolmogorovSmirnov test was used to determine whether the data met the assumptions for parametric tests. Independent-samples $t$-tests (for normally distributed data) and Mann Whitney-U analysis (for non-normally distributed data) were used to determine group differences. Data were analyzed using SPSS 17 for Windows (Statistical Package for the Social Sciences) at a significance level of 0.05 .

\section{Results}

Table 1 shows the demographic characteristics of the participants and duration of the procedures. Groups KP and MM did not significantly differ by age, gender, Body Mass Index (BMI), ASA scores, duration of each group, and ERCP difficulties which were classified by ASGE criteria (Table 1) and types of indications for ERCP (Table 2) ( $p>0.05)$.

The groups did not significantly differ by SBP at $\mathrm{T}_{0}$. However, Group KP had significantly higher DBP at $\mathrm{T}_{0}$, $\mathrm{T}_{1}, \mathrm{~T}_{2}$, and $\mathrm{T}_{3}$ and higher SBP, $\mathrm{SPO}_{2}$, and HR (Table 3) at $\mathrm{T}_{1}, \mathrm{~T}_{2}$, and $\mathrm{T}_{3}$ than Group MM $(P=0.0001)$.

Although Group KP had higher BIS scores at $\mathrm{T}_{0}$ than Group MM, the latter had significantly higher BIS scores at $\mathrm{T}_{1}, \mathrm{~T}_{2}$, and $\mathrm{T}_{3}$ than the former $(p<0.0001)$ (Figure 1). Table 3 shows the categorical BIS scores and depression distribution and differences between the two groups.

Table 6 presents the comparison of the primary outcomes of the two groups. The results show that Group MM had a higher time to achieve RSS scores $\geq 4(p<0.001)$ (Table 4$)$ and MAS scores $\geq 9$ (Table 5), and total dose of propofol as rescue sedation than Group MM $(p<0.001)$.

In Group KP, two patients (2.7\%) had cough and two patients $(2.7 \%)$ needed restraint. In Group MM, three patients $(4 \%)$ had cough, two patients $(2.7 \%)$ had gag reflex, and four patients (5.3\%) needed restraint, indicating no statistically significant difference between the two

Table I Demographic characteristics and duration of the procedures

\begin{tabular}{|c|c|c|c|}
\hline & $\begin{array}{l}\text { Group } \\
\text { KP } \\
(n=75)\end{array}$ & $\begin{array}{l}\text { Group MM } \\
(n=75)\end{array}$ & p-value \\
\hline Age (years) & $88.15 \pm 3.11$ & $87.99 \pm 2.62$ & $0.510^{\mathrm{a}}$ \\
\hline Female, n (\%) & 47 (62.7) & $34(45.3)$ & $0.033^{c}$ \\
\hline Male, n (\%) & $28(37.3)$ & $4 \mathrm{I}(54.7)$ & $0.033^{c}$ \\
\hline BMI & $24.16 \pm 2.50$ & $24.20 \pm 2.28$ & $0.930^{b}$ \\
\hline \multicolumn{4}{|l|}{ ASA, n (\%) } \\
\hline $\begin{array}{l}\text { III } \\
\text { IV }\end{array}$ & $\begin{array}{l}43(57.3) \\
32(42.7)\end{array}$ & $\begin{array}{l}41(54.7) \\
34(45.3)\end{array}$ & $0.742^{c}$ \\
\hline $\begin{array}{l}\text { Duration of } \\
\text { procedures }\end{array}$ & $41.52 \pm 13.19$ & $49.15 \pm 13.12$ & $0.000 l^{a}$ \\
\hline \multicolumn{4}{|l|}{$\begin{array}{l}\text { Grade of ERCP } \\
\text { procedures }\end{array}$} \\
\hline $\begin{array}{l}\text { Grade I, n (\%) } \\
\text { Grade II, n (\%) } \\
\text { Grade III, n (\%) }\end{array}$ & $\begin{array}{l}19(25.3) \\
50(66.7) \\
6(8.0)\end{array}$ & $\begin{array}{l}13(17.3) \\
57(76.0) \\
5(6.7)\end{array}$ & $0.433^{c}$ \\
\hline
\end{tabular}

Notes: aMann Whitney U-test, ' Independent samples $t$-test, 'chi-square test. Abbreviations: ASA, American Society of Anesthesiologists; BMI, body mass index; ERCP, endoscopic retrograde cholangiopancreatography

Table 2 Diagnosis of the patients

\begin{tabular}{|c|c|c|c|}
\hline & $\begin{array}{l}\text { Group KP } \\
(n=75)\end{array}$ & $\begin{array}{l}\text { Group MM } \\
(n=75)\end{array}$ & p-value \\
\hline \multicolumn{4}{|l|}{ Indication type } \\
\hline $\begin{array}{l}\text { Choledoc stone, n (\%) } \\
\text { Cholangitis, n (\%) } \\
\text { Pancreatitis*, n (\%) } \\
\text { Malignancy, n (\%) }\end{array}$ & $\begin{array}{l}40(53.3) \\
21(28.0) \\
6(8.0) \\
5(6.7)\end{array}$ & $\begin{array}{l}43(57.3) \\
15(20.0) \\
6(8.0) \\
10(13.3)\end{array}$ & $0.425^{\mathrm{a}}$ \\
\hline \multicolumn{4}{|l|}{$\begin{array}{l}\text { Sepsis, without bili- } \\
\text { ary pathology } \\
\text { n (\%) }\end{array}$} \\
\hline $\begin{array}{l}\text { Cholangitis } \\
\text { Malignancy seconder } \\
\text { Calculi and sludge }\end{array}$ & $\begin{array}{l}3(4.0) \\
3(4.0) \\
18(24.0)\end{array}$ & $\begin{array}{l}1(1.3) \\
5(6.0) \\
10(13)\end{array}$ & $>0.05$ \\
\hline
\end{tabular}

Note: ${ }^{a}$ chi-square test. 
Table 3 Time-dependent changes in circulatory dynamics, Categorical BIS scores, distribution, and differences between patient groups*

\begin{tabular}{|c|c|c|c|}
\hline & $\begin{array}{l}\text { Group KP } \\
(n=75)\end{array}$ & $\begin{array}{l}\text { Group MM } \\
(n=75)\end{array}$ & p-value \\
\hline \multicolumn{4}{|l|}{ SBP } \\
\hline $\mathrm{T}_{0}$ & $148.33 \pm 18.83$ & $141.77 \pm 22.69$ & $0.056^{\mathrm{a}}$ \\
\hline $\mathrm{T}_{1}$ & $139.96 \pm 19.73$ & $1 \mid 4.00 \pm 19.73$ & $0.0002^{\mathrm{a}}$ \\
\hline $\mathrm{T}_{2}$ & $136.04 \pm 20.45$ & $116.36 \pm 20.93$ & $0.000 \mathrm{I}^{\mathrm{a}}$ \\
\hline $\mathrm{T}_{3}$ & $132.44 \pm 19.92$ & $\mid 16.31 \pm 17.26$ & $0.000 \mathrm{I}^{\mathrm{a}}$ \\
\hline \multicolumn{4}{|l|}{ DBP } \\
\hline $\mathrm{T}_{0}$ & $71.19 \pm 12.68$ & $64.21 \pm 12.60$ & $0.00 I^{b}$ \\
\hline$T_{1}$ & $62.28 \pm 9.55$ & $54.25 \pm \mid 1.01$ & $0.000 \mathrm{I}^{\mathrm{b}}$ \\
\hline $\mathrm{T}_{2}$ & $60.51 \pm 7.85$ & $54.11 \pm 8.34$ & $0.000 \mathrm{I}^{\mathrm{b}}$ \\
\hline $\mathrm{T}_{3}$ & $59.91 \pm 9.51$ & $52.80 \pm 6.03$ & $0.0001^{\mathrm{b}}$ \\
\hline \multicolumn{4}{|l|}{$H R$} \\
\hline $\mathrm{T}_{0}$ & $70.39 \pm 11.10$ & $70.03 \pm \mid 1.61$ & $0.846^{\mathrm{a}}$ \\
\hline $\mathrm{T}_{1}$ & $65.49 \pm 11.15$ & $70.19 \pm 9.14$ & $0.005^{\mathrm{a}}$ \\
\hline $\mathrm{T}_{2}$ & $63.60 \pm 8.47$ & $69.59 \pm 7.22$ & $0.000 \mathrm{I}^{\mathrm{a}}$ \\
\hline $\mathrm{T}_{3}$ & $70.36 \pm 6.74$ & $74.21 \pm 5.04$ & $0.000 \mathrm{I}^{\mathrm{a}}$ \\
\hline \multicolumn{4}{|l|}{$\mathrm{SPO}_{2}$} \\
\hline $\mathrm{T}_{0}$ & $93.40 \pm 2.49$ & $93.00 \pm 2.75$ & $0.267^{\mathrm{b}}$ \\
\hline $\mathrm{T}_{1}$ & $92.29 \pm 2.09$ & $88.93 \pm 2.86$ & $0.000 \mathrm{I}^{\mathrm{b}}$ \\
\hline $\mathrm{T}_{2}$ & $91.95 \pm 1.99$ & $89.60 \pm 2.66$ & $0.0001^{\mathrm{b}}$ \\
\hline $\mathrm{T}_{3}$ & $91.79 \pm 2.00$ & $90.09 \pm 1.66$ & $0.0001^{b}$ \\
\hline \multicolumn{4}{|c|}{$T_{0}$ BIS score, $n$ (\%) } \\
\hline$<60$ & - & $4(5.3)$ & \\
\hline $60-80$ & $73(97.3)$ & 7I (94.7) & $0.015^{c}$ \\
\hline$>80$ & $2(2.7)$ & - & \\
\hline \multicolumn{4}{|c|}{$T_{1}$ BIS score, $n$ (\%) } \\
\hline$<60$ & $5(6.7)$ & - & \\
\hline $60-80$ & $70(93.3)$ & $63(84.0)$ & $0.0001^{c}$ \\
\hline$>80$ & - & $12(16.0)$ & \\
\hline \multicolumn{4}{|c|}{$T_{2}$ BIS score, $n$ (\%) } \\
\hline$<60$ & $5(6.7)$ & - & \\
\hline $60-80$ & $69(92.0)$ & 61 (8I.3) & $0.0001^{c}$ \\
\hline$>80$ & $\mathrm{I}(\mathrm{I} .3)$ & 14 (I8.7) & \\
\hline \multicolumn{4}{|c|}{$T_{3}$ BIS Score, $n(\%)$} \\
\hline$<60$ & $2(2.7)$ & - & \\
\hline $60-80$ & $72(96.0)$ & $72(96.0)$ & $0.148^{c}$ \\
\hline$>80$ & I (I.3) & $3(4.0)$ & \\
\hline
\end{tabular}

Notes: ${ }^{a}$ Independent samples $t$-test, ${ }^{b}$ Mann Whitney U-test, ${ }^{c}$ chi-square with linear likelihood ratio. *Since parameters were compared separately, Bonferroni Correction was not usable.

Abbreviations: BIS, Bispectral index; DBP, Diastolic blood pressure; SBP, Systolic blood pressure.
Table 4 Ramsay sedation scale

\begin{tabular}{|l|l|}
\hline \multicolumn{2}{|l|}{ Ramsay sedation scale } \\
\hline 1 & Patient is anxious and agitated or restless, or both \\
2 & Patient is co-operative, oriented, and tranquil \\
3 & Patient responds to commands only \\
4 & Patient exhibits a brisk response to light glabellar tap or loud \\
& auditory stimulus \\
5 & Patient exhibits a sluggish response to light glabellar tap or loud \\
6 & auditory stimulus \\
\hline
\end{tabular}

Note: Group MM had significantly higher FPS than Group KP $(P<0.000 \mathrm{I})$ (Figures 2 and 3).

Abbreviation: FPS, facial pain score.

Table 5 Time to achieve RSS, MAS, and total dose of rescue medication

\begin{tabular}{|l|l|l|l|}
\hline Variable & $\begin{array}{l}\text { Group } \\
\text { KP }\end{array}$ & Group MM & p-value \\
\hline Time to RSS 4 (min) & $3.21 \pm 0.4 \mathrm{I}$ & $5.4 I \pm 0.49$ & $<0.00 \mathrm{I}$ \\
$\begin{array}{l}\text { Time to MAS (min) } \\
\begin{array}{l}\text { Total dose of propofol as } \\
\text { rescue sedation }\end{array}\end{array}$ & $10.93 \pm 0.25$ & $1 \mathrm{I} . \mathrm{II} \pm 0.3 \mathrm{I}$ & $<0.00 \mathrm{I}$ \\
\hline
\end{tabular}

Abbreviations: MAS, Modified Aldrete Score; RSS, Ramsay Sedation Score.

groups $(p>0.05)$. During recovery, three patients had hypotension, one bradycardia, four PONV and three agitation/delirium in Group KP. On the other hand, four had hypotension, three bradycardia, and six PONV in Group MM during recovery $(p>0.05)$ (Table 6).

\section{Discussion}

Ketamine is a derivate of phencyclidine, which is a non-competitive N-methyl-D-aspartate (NMDA) receptor antagonist binding to opioid and sigma receptors. Ketamine, with its rapid onset and short duration, leads to a condition referred to as "dissociative anesthesia", resulting in amnesia and analgesia with little or no cardio-respiratory depression. The use of ketamine alone as a sedative agent has been limited due to its propensity to cause frightening and vivid irrelevant emergence reactions and nausea-vomiting and its sympathomimetic effects. ${ }^{8,9}$ Ketamine is watersoluble and lipophilic. The onset of action of intravenously administered ketamine is rapid, ranging from 15-30 minutes. The recommended sedation dose of ketamine is $0.5-1 \mathrm{mg} / \mathrm{kg}$. 
Table 6 Sedation related complications during the procedure and the recovery

\begin{tabular}{|l|l|l|l|}
\hline & $\begin{array}{l}\text { Group KP } \\
(\mathbf{n = 7 5 )}\end{array}$ & $\begin{array}{l}\text { Group MM } \\
(\mathbf{n = 7 5 )}\end{array}$ & p-value \\
\hline Bradycardia, n (\%) & $2(2.7)$ & $17(22.7)$ & $<0.05^{\mathrm{a}}$ \\
Apnea, n (\%) & $3(4.0)$ & $22(29.3)$ & $<0.05^{\mathrm{a}}$ \\
Hypotension, n (\%) & $\mathrm{I}(\mathrm{I} .3)$ & $3(4.0)$ & $0.300^{\mathrm{a}}$ \\
Desaturation n (\%) & $9(12.0)$ & $13(17.3)$ & $0.356^{\mathrm{a}}$ \\
Coughs, n (\%) & $2(2.7)$ & $3(4.0)$ & 0.648 \\
Gagging, n (\%) & $0(0.0)$ & $2(2.7)$ & 0.094 \\
Restraint, n (\%) & $2(2.7)$ & $4(5.3)$ & 0.400 \\
\hline During recovery & & & \\
\hline Respiratory depres- & 0 & 0 & N/A \\
sion, n (\%) & & $4(5.3)$ & 0.698 \\
Hypotension & $3(4.0)$ & $3(4.0)$ & 0.300 \\
Bradycardia & $\mathrm{I}(\mathrm{I} .3)$ & $6(8.0)$ & $0.5 / 3$ \\
PONV & $4(5.3)$ & 0 & N/A \\
Apnea & 0 & 0 & N/A \\
Agitation/delirium & $3(4.0)$ & &
\end{tabular}

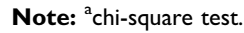

Prepared in a $10 \%$ lipid emulsion, propofol is a lipophilic alkyl phenol derivative, which is a shortacting sedative ( 10 minutes, depending on dose) with a rapid onset of action ( $<1$ minute). Its clearance is not affected by renal or hepatic dysfunction, as it has no active metabolites. Propofol can be used as a short-term sedative agent starting from a dose of $1 \mathrm{mg} / \mathrm{kg}$ and then titrated to effect with incremental doses of $0.5 \mathrm{mg} / \mathrm{kg}$ in adults. Propofol has respiratory and cardiovascular depressant effects. $^{12-15}$

Propofol is a strong anesthetic with no property of internal analgesia that reduces respiratory depression and blood pressure in patients. Using opioid with propofol increases the frequency of respiratory depression and reduces the amount of propofol required. Ketamine is a safe sedative analgesic agent that can be used with propofol. It causes no respiratory depression and increases blood pressure and heartbeat thanks to its sympathetic effects. $^{13-15}$ This is the reason why we used ketamine to decrease the unwanted side-effects of propofol. We found that ketofol reduced the incidence of sedation-related complications and maintained hemodynamic stability with an adequate level of sedation in very elderly patients undergoing ERCP.

Many studies have shown that the combination of propofol and ketamine in low doses can be used to maintain hemodynamic stability and to avoid side-effects that may occur when either of them is individually administered in large doses. ${ }^{13-15,21-23}$ There are numerous studies investigating the ideal dose of the combination of propofol and ketamine for deep sedation. There are, however, no studies that investigate the best combination dose for elderly patients.

Participants in Group KP, who received a 1:1 combination of ketamine and propofol (ketofol), had better hemodynamical stability in SBP, DBP, $\mathrm{HR}$, and $\mathrm{SPO}_{2}$ and higher BIS scores than those in Group MM. This result indicates that ketamine was effective in counteracting the hemodynamic depression of propofol in high-risk (ASA III and IV) oldest old patients.

Our results are consistent with those of several studies that used ketofol in conjunction with regional anesthesia. Throughout our study, 1,337 patients under the age of 85 years underwent ERCP in our institution. We used ketofol anesthesia in 1,207 of them and observed no major anesthesia-related complications. Rapeport et $\mathrm{al}^{24}$ reported that ketofol infusion $(1: 1)$ is a safe and effective sedative and analgesic agent that can be used to achieve adequate sedation under regional anesthesia in high risk patients. Micdadqy et $\mathrm{al}^{25}$ administered the same dose of ketofol (1:1) in conjunction with regional anesthesia, and reported no episode of cardiovascular and respiratory failure. Andolfatto and Willman ${ }^{26}$ used ketofol (1:1) and found adequate sedation in emergency procedural sedation. Eberl et $\mathrm{al}^{28}$ suggested that ketamine and propofol be used together to reduce the total amount of propofol.

Olson et $\mathrm{al}^{29}$ compared ketofol $(0.75 \mathrm{mg} / \mathrm{kg})$ and propofol $(1,5 \mathrm{mg} / \mathrm{kg})$ in general anesthesia at induction and reported less myocardial depression and vasodilation in the ketofol group. Lemoel et $\mathrm{al}^{30}$ also reported better hemodynamic results with respiratory stability in the ketofol group.

Benzodiazepines have frequently been used in endoscopic procedures in recent years. However, studies report adverse effects such as respiratory depression, especially in very elderly patients with comorbidities. Paradoxical excitement is a serious adverse effect observed in up to $10-15 \%$ of elderly patients. ${ }^{16,17}$

Midazolam, which is a benzodiazepine, is widely used alone or in combination with an opiate such as meperidine, due to its quick onset of action and relatively short duration of effect. Nevertheless, using a combination of midazolam and an opiate extends their effects, increases the likelihood of respiratory depression, and prolongs the recovery period. ${ }^{23,24}$

Following infusion, propofol is characterized by rapid distribution and elimination without any cumulative effect. 

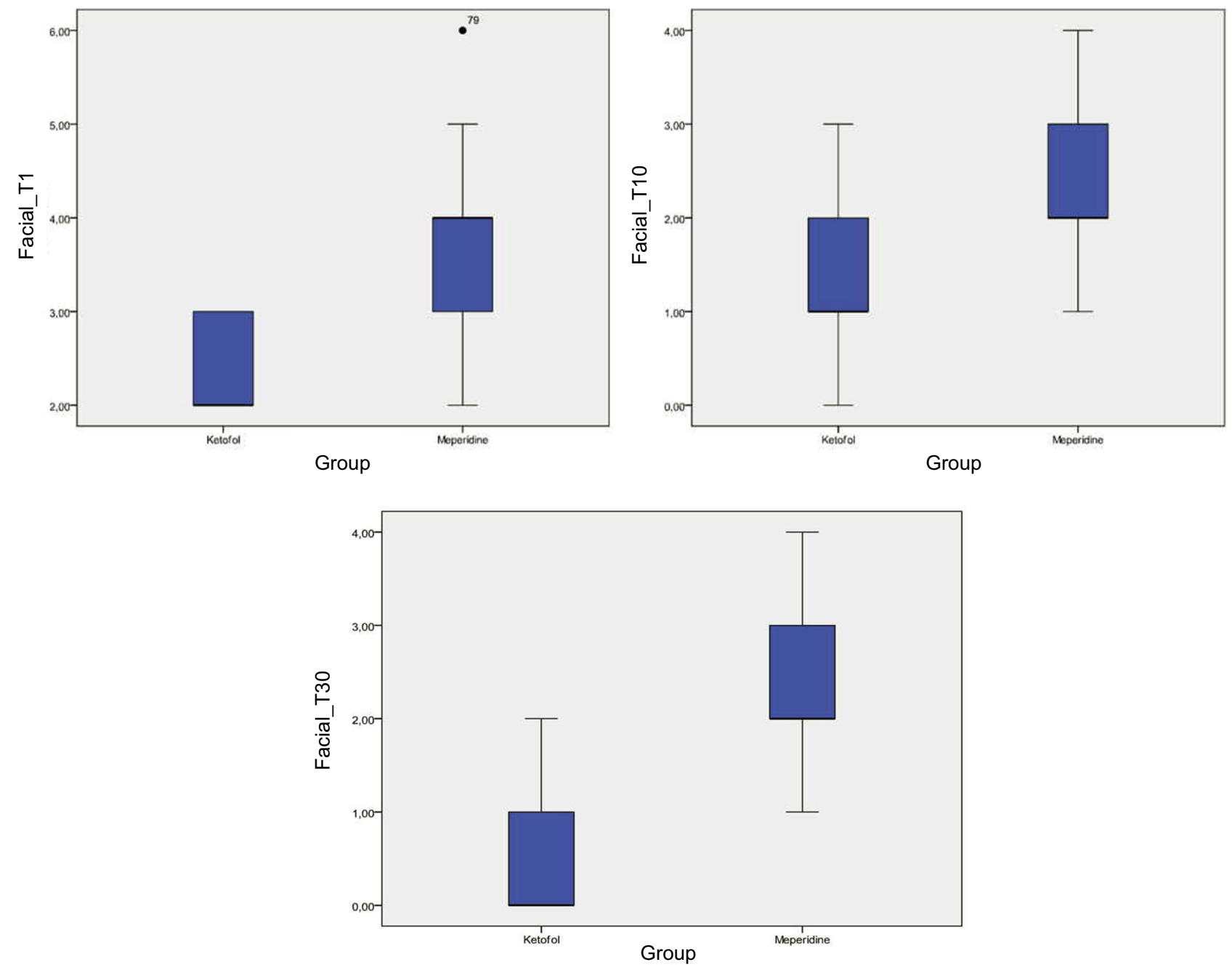

Figure 3 Distribution of facial pain scores of each group.

It is, however, much narrower than midazolam, and, therefore, should be more closely monitored to differentiate sedation levels. Propofol used ${ }^{25-29}$ in ERCP has been reported to provide more cooperation, a shorter recovery period, and a better sedation quality than midazolam

We observed apnea in 22 patients in Group MM at the beginning of the procedure. The head-tilt/chin-lift maneuver was used to open the airway of 17 of them. Mask ventilation was used in five of them. Atropine was administered to 17 of them, due to apnea accompanied by bradycardia. In three patients in Group KP, we observed respiratory depression and apnea that were resolved after the aspiration of the secretions. No cardiac arrest was observed, and no patients were admitted to the intensive care unit.

ERCP is an invasive procedure in which papillary balloon expansion and dilation can be painful. FPS was used for pain assessment during the procedure because all our patients were older than 85 years old and difficult to communicate with due to impaired cognitive functions. We, therefore, relied on facial expressions during the procedure and recovery period. Group MM had a higher FPS scores at $T_{1}$ and $T_{3}$, which might be due to the fact that we used a low dose of meperidine to prevent respiratory depression. The low FPS scores of Group KP might be due to the analgesic properties of ketamine. Our results are consistent with those of Hassan et al, who reported that ketofol sedation (1:1) was adequate and painless. Tosun also reported that ketofol provided effective sedation and analgesia.

Nejati et $\mathrm{al}^{27}$ conducted a randomized prospective study in an emergency department for the reduction of bone fractures and compared ketofol (1:1) with a combination of midazolam and fentanyl (MF). They reported that Group KP, with adequate sedation, had significantly lower pain scores than Group MF. ${ }^{27}$ 
Based on change in the level of alertness, BIS is a non-invasive technology that provides valuable information that can be used to assess the level of sedation. A numeric scale ranging from $0-100$ has been has developed. In recent years, numerous studies have reported a good correlation between BIS values and clinical scores of sedation (ie, RSS) in outpatient procedures. $^{18,19}$ There are some studies reporting no correlation BIS and unconsciousness when ketamine is used alone or in combination with propofol. There are no data, up to date, on the use of BIS on oldest old patients. ${ }^{10-12,20}$ In our study, BIS was used to assess the depth of sedation. Patients in Group KP had lower BIS scores at $T_{1}, T_{2}$, and $T_{3}$, indicating that they achieved an adequate depth of sedation to end the procedure successfully.

Propofol was administered as rescue medication to reduce movements, cough, and restraints. Group KP was given significantly less rescue medication.

Group KP achieved MAS scores faster than Group MM. The longer recovery time in Group MM can be explained by the slower clearance meperidine.

Group MM had higher rates of nausea and vomiting. Propofol is an efficient anti-emetic agent which reduces the emetic properties of ketamine. Higher rates of hypotension in Group MM might, therefore, be associated with increased incidence of nausea and vomiting. ${ }^{13-15}$

Ketofol (1:1) provided adequate analgesia and sedation for ERCP and resulted in less oxygen desaturation than did the combination of midazolam meperidine in the very elderly patients. Adverse effects can occur in sedation procedures, and, therefore, close monitoring and cardiorespiratory support should be ready during ERCP.

\section{Conclusion}

Ketofol is more effective and safer than the combination of midazolam and meperidine in order to achieve adequate sedation in ERCP patients in a shorter period of time with lower doses. Ketofol provides better hemodynamic stability and results in lower rates of nausea/ vomiting and respiratory complications than does midazolam-meperidine. We believe that ketofol is a better choice than the combination of midazolam and meperidine for patients who need a shorter period of induction at the onset of sedation. Ketofol is a safe alternative to conventional sedation regimens during ERCP for oldest old patients.

\section{Acknowledgments}

We thank Kadir Y1lmaz with his valuable statistics support.

\section{Disclosure}

The authors declare no conflicts of interest in this work.

\section{References}

1. Martindale SJ. Anaesthetic considerations during endoscopic retrograde cholangiopancreatography. Anaesth Intensive Care. 2006;34:475-480. doi:10.1177/0310057X0603400401

2. Metzner J, Posner KL, Domino KB. The risk and safety of anesthesia at remote locations: the US closed claims analysis. Curr Opin Anaesthesiol. 2009;22:502-508. doi:10.1097/ACO.0b013e32832d ba50

3. Hinkelbein J, Lamperti M, Akeson J, et al. European Society of Anaesthesiology and European Board of Anaesthesiology guidelines for procedural sedation and analgesia in adults. Eur J Anaesthesiol. 2018;35(1):6-24. doi:10.1097/EJA.0000000000000683

4. Patel S, Vargo JJ, Khandwala F. Deep sedation occurs frequently during elective endoscopy with meperidine and midazolam. Am J Gastroenterol. 2005;100:2689-2695. doi:10.1111/j.15720241.2005.00320.x

5. Jokelainen J, Udd M, Kylänpää L, et al. How patient-controlled sedation is adopted in clinical practice of sedation for endoscopic retrograde cholangiopancreatography? A prospective study of 1196 cases. Scand J Gastroenterol. 2017;52(2):166-172. doi:10.1080/ 00365521.2016 .1242024

6. Zizza CA, Ellison KJ, Wernette CM. Total water intakes of community-living middle-old and oldest-old adults. J Gerontol Ser A. 2009;64A(4):481-486. doi:10.1093/gerona/gln045

7. Dumonceau JM, Riphaus A, Aparicio JR, et al. European Society of Gastrointestinal Endoscopy, European Society of Gastroenterology and Endoscopy Nurses and associates, and the European Society of Anaesthesiology Guideline: non-anaesthesiologist administration of propofol for gi endoscopy. Eur J Anaesthesiol. 2010;27:1016-1030. doi:10.1097/EJA.0b013e32834136bf

8. Harvey M, Sleigh J, Voss L, et al. Development of rapidly metabolized and ultra-short-acting ketamine analogs. Anesth Analg. 2015;121(4):925-933. doi:10.1213/ANE.0000000000000719

9. Tobias JD, Leder M. Procedural sedation: a review of sedative agents, monitoring and management of complications. Saudi $J$ Anaesth. 2011;5(4):395-410. doi:10.4103/1658-354X.87270

10. Willman EV, Andolfatto G. A prospective evaluation of "Ketofol" (ketamine/propofol combination) for procedural sedation and analgesia in the emergency department. Ann Emerg Med. 2007;49:23-30. doi:10.1016/j.annemergmed.2006.08.002

11. Mortero RF, Clark LD, Tolan MM, Metz RJ, Tsueda K, Sheppard RA. The effects of small-dose ketamine on propofol sedation: respiration, postoperative mood, perception, cognition, and pain. Anesth Analg. 2001;92:1465-9. doi:10.1097/00000539-200106000-00022

12. Akin A, Guler G, Esmaoglu A, Bedirli N, Boyaci AA. comparison of fentanyl-propofol with a ketamine-propofol combination for sedation during endome-trial biopsy. J Clin Anesth. 2005;17:187-190. doi:10.1016/j.jclinane.2004.06.019

13. Messenger DW, Murray HE, Dungey PE, Van Vlymen J, Sivilotti ML. Subdissociative-dose ketamine versus fentanyl for analgesia during propofol procedural sedation: a randomized clinical trial. Acad Emerg Med. 2008;15(10):877-886. doi:10.1111/j.1553-2712.2008.00219.x

14. Riham H, Wael ES. Ketamine/propofol versus fentanyl/propofol for sedating obese patients undergoing endoscopic retrograde cholangiopancreatography (ERCP). Egypt J Anesth. 2013;29:207-211. doi:10.1016/j.egja.2013.02.009 
15. Wadhwa V, Issa D, Garg S, Lopez R, Sanaka MR, Vargo JJ. Similar risk of cardiopulmonary adverse events between propofol and traditional anesthesia for gastrointestinal endoscopy: a systematic review and meta-analysis. Clin Gastroenterol Hepatol. 2017;15(2):194-206. doi:10.1016/j.cgh.2016.07.013

16. Zhang J, Huang Y, Li Z, Li J, Liu K, Li C. Sedation and use of analgesics in endoscopic retrograde cholangiopancreatography: a double-blind comparison study of meperidine/midazolam, remifentanil/ midazolam,and remifentanil alone. Int J Clin Pharmacol Ther. 2016;54(11):872-879. doi:10.5414/CP202408

17. Lee BS, Ryu J, Lee SH, et al. Midazolam with meperidine and dexmedetomidine vs midazolam with meperidine for sedation during ERCP: prospective randomized double blinded trial. Endoscopy. 2014;46(4):291-298. doi:10.1055/s-0033-1358909

18. Yüksel O, Parlak E, Köklü S, Ertugrul I, Tunç B, Sahin B. Conscious sedation during endoscopic retrograde cholangiopancreatography: midazolam or midazolam plus meperidine? Eur J Gastroenterol Hepatol. 2007;19:1002-1006. doi:10.1097/MEG.0b013e3282cf5167

19. Al-Sammak Z, Al-Falaki MM, Gamal HM. Predictor of sedation during endoscopic retrograde cholangiopancreatography-bispectral index vs clinical assessment. Middle East J Anesthesiol. 2005;18:141-148.

20. De Oliveira GS Jr, Kendall MC, Marcus RJ, McCarthy RJ. The relationship between the Bispectral Index (BIS) and the Observer Alertness of Sedation Scale (OASS) scores during propofol sedation with and without ketamine: a randomized, double blinded, placebo controlled clinical trial. J Clin Monit Comput. 2016;30(4):495-501. doi:10.1007/s10877-015-9745-0

21. Hassan HI. Dexmedetomidine versus ketofol for moderate sedation in Endoscopic Retrograde Cholangiopancreatography (ERCP) comparative study. Egypt $J$ Anesth. 2015;31:15-21. doi:10.1016/j. egja.2014.11.002

22. Tosun Z, Akin A, Guler G, Esmaoglu A, Boyaci A. Dexmedetomidine-ketamine and propofol-ketamine combinations for anesthesia in spontaneously breathing pediatric patients undergoing cardiac catheterization. J Cardiothorac Vasc Anest. 2006;20:515-519. doi:10.1053/j.jvca.2005.07.018
23. Miller MA, Levy P, Patel MM. Procedural sedation and analgesia in the emergency department: what are the risks? Emerg Med Clin North Am. 2005;23:551-572. doi:10.1016/j.emc.2004. 12.016

24. Rapeport DA, Martyr JW, Wang LP. The use of "ketofol" (ketaminepropofol admixture) infusion in conjunction with regional anaesthesia. Anaesth Intensive Care. 2009;37(1):121-123. doi:10.1177/ 0310057 X0903700108

25. Miqdady MI, Hayajneh WA, Abdelhadi R, Gilger MA. Ketamine and midazolam sedation for Pediatric gastrointestinal endoscopy in the Arab World. World J Gastroenterol. 2011;17:3630-3635. doi:10.3748/wjg.v17.i31.3630

26. Andolfatto G, Willman E. A prospective case series of single-syringe ketamine-propofol (Ketofol) for emergency department procedural sedation and analgesia in adults. Acad Emerg Med. 2011;18:237-245. doi:10.1111/j.1553-2712.2011.01 010.x

27. Nejati A, Moharari RS, Asraf H, Labaf A, Golshani K. Ketamine/ propofol versus midazolam/fentanyl for procedural sedation and analgesia in the emergency department: a randomized, prospective, double-blind trial. Acad Emerg Med. 2011;18(8):800-806. doi:10.1111/j.1553-2712.2011.01133.x

28. Eberl S, Koers L, Van Hooft JE, et al. Sedation with propofol during ERCP: is the combination with ketamine more effective and safer than with alfentanil? Study protocol for a randomized controlled trial. Trials. 2017;18(1):472. doi:10.1186/s13063-0172197-8

29. Olson AN, Rao WR, Marienau ME, Smischney NJ. Period prevalence of ketamine-propofol admixture "Ketofol" in the operating room among anesthesia providers at an academic medical center. Med Sci Monit. 2015;21:1737-1744. doi:10.12659/ MSM.893944

30. Lemoel F, Contenti J, Giolito D, et al. Adverse events with ketamine versus ketofol for procedural sedation on adults: a double-blind, randomized controlled trial. Acad Emerg Med. 2017;24 (12):1441-1449. doi:10.1111/acem.13226
Therapeutics and Clinical Risk Management

\section{Publish your work in this journal}

Therapeutics and Clinical Risk Management is an international, peerreviewed journal of clinical therapeutics and risk management, focusing on concise rapid reporting of clinical studies in all therapeutic areas, outcomes, safety, and programs for the effective, safe, and sustained use of medicines. This journal is indexed on PubMed Central, CAS,
EMBase, Scopus and the Elsevier Bibliographic databases. The manuscript management system is completely online and includes a very quick and fair peer-review system, which is all easy to use. Visit http://www.dovepress.com/testimonials.php to read real quotes from published authors. 